\title{
Demografia urbana e políticas sociais
}

\author{
Haroldo da Gama Torres*
}

\begin{abstract}
Este artigo busca discutir as possíveis contribuições da análise demográfica para as políticas sociais de caráter urbano. Em particular, são apresentadas dez situações do processo de formulação de políticas sociais, nas quais a informação demográfica pode ter contribuições relevantes. Adicionalmente, são destacados dois outros aspectos importantes: o problema da desagregação espacial da informação; e a necessidade do recurso a sistemas de informação geográfica.
\end{abstract}

Palavras-chave: Demografia aplicada. Políticas públicas. Sistemas de informação geográfica. Demografia urbana.

\section{Introdução}

A dinâmica demográfica intra-urbana constitui um enorme desafio do ponto de vista do planejamento das políticas sociais, sobretudo num país crescentemente metropolitano como o Brasil. Tal desafio tem sido enfrentado por administrações municipais e estaduais dotadas de sistemas de informação muitas vezes inadequados e envolvendo grupos técnicos com significativas deficiências no uso e tratamento da informação disponível. Ao mesmo tempo, existe nessa área um significativo campo de trabalho para profissionais com formação em estudos de população e demografia, potencial precariamente preenchido, de modo geral, pelos demógrafos brasileiros.

De fato, em que pese a continuada expectativa desses profissionais de que a análise demográfica contribua efetivamente para o planejamento e execução das políticas sociais, nem sempre essa contribuição se verifica, sobretudo no caso de políticas sociais geridas em escala local. Se é verdade que no âmbito de políticas nacionais - como as de educação, saúde e previdência social - a contribuição dos demógrafos tem sido relevante, vale também destacar que, no plano das milhares de iniciativas de planejamento realizadas anualmente no Brasil nas escalas estadual e municipal, poucas vezes essa contribuição é buscada, e mesmo quando verificada assume um caráter relativamente limitado, diante da enorme demanda existente.

A baixa participação dos demógrafos brasileiros em atividades de planejamento subnacional tem, provavelmente, diversas explicações. Por um lado, os gestores locais possuem pouca familiaridade com as técnicas envolvidas e com a informação demográfica, desconhecendo seu potencial e, assim, não demandando-as adequadamente. Por outro, essas técnicas demográficas estão menos desenvolvidas no que se refere ao problema das pequenas áreas. Além disso, muitas das análises necessárias

\footnotetext{
* Pesquisador do Cebrap e coordenador de Transferência de Tecnologia do Centro de Estudos da Metrópole (CEM-Cebrap).
} 
nessa escala passaram a requer mais recentemente a utilização dos chamados sistemas de informação geográfica (SIG), ${ }^{1}$ que nem sempre estão disponíveis localmente, seja porque o município ou Estado não os desenvolveu, seja porque os órgãos estatísticos nacional e estaduais não disseminam dados e mapas digitais compatíveis com tais sistemas (TORRES, 2002 e 2005).

Paradoxalmente, vive-se um momento de explosão na produção de indicadores diversos, como o projeto do IDH evidencia exemplarmente. Por todo o Brasil, agentes públicos e grupos profissionais propõemse a construir indicadores como subsídio a políticas públicas, muitas vezes sem conhecer mais profundamente as restrições impostas pelos dados, as limitações relacionadas aos denominadores populacionais adotados e o significado analítico de certas escolhas decorrentes da produção de índices, tais como - por exemplo - a questão da ponderação das variáveis consideradas (JANUZZI, 2001).

Acredita-se que uma urgente tarefa dos demógrafos brasileiros está em compreender as condições em que se dá a demanda por informações demográficas por parte dos gestores públicos e em produzir respostas ágeis e adequadas. Trata-se de colocar-se no lugar dos consumidores potenciais desse tipo de informação e pensar as condições concretas de produção dessas políticas. Por exemplo, as decisões envolvidas são realizadas num prazo de tempo incompatível com a elaboração de análises mais sofisticadas. Em outros casos, verificam-se inconsistências importantes entre as unidades de análises utilizadas nos estudos demográficos e as requeridas pelo usuário potencial.

Apesar dessas dificuldades na interpretação de informações, as administrações locais são cada vez mais importantes na gestão das políticas sociais. A partir da Constituição de 1988, essas políticas no
Brasil têm sido crescentemente descentralizadas. Observa-se um processo de descentralização bastante avançado no caso das políticas de saúde e educação, mas que também vem sendo ensaiado para políticas como as de habitação, saneamento e transferência de renda (ARRETCHE, 1998). Nesse novo contexto, as transferências derivadas dos processos de descentralização devem se basear em critérios sociodemográficos e as informações sociodemográficas, nas escalas regional e local, devem contribuir para estabelecer critérios de execução orçamentária e para monitorar o processo a partir de indicadores de cobertura e/ou de qualidade do serviço.

Para aprofundar essa discussão, apresenta-se, inicialmente, um conjunto de dez situações em que a informação sociodemográfica pode ser demandada no âmbito das políticas sociais locais. A seguir, aprofunda-se esse debate refletindo sobre o problema da desagregação espacial da informação, aspecto muitas vezes reivindicado pelos gestores públicos que operam em grandes áreas urbanas ou metropolitanas, mas normalmente negligenciado pelos demógrafos.

\section{Quando a informação sociodemográfica é demandada em escala local?}

Nessa seção, procura-se identificar diferentes situações em que a informação sociodemográfica poderia ser ou vem sendo demandada em escala local. O conjunto de situações aqui destacado não é exaustivo, sendo que os temas considerados são principalmente fruto da experiência profissional em diversos projetos junto a governos estaduais e municipais, realizados por organizações como a Fundação Seade e o Cebrap, e a partir de diálogo com outros profissionais e organizações atuantes na área. ${ }^{2}$ Apresentam-se, a seguir, os dez tipos de situação mais comuns identificados pelo autor.

\footnotetext{
${ }^{1}$ Para uma discussão geral sobre o SIG, ver Demers (2000) e Martin (1996).

${ }^{2}$ Destacam-se, em particular, as discussões realizadas no âmbito do Celade (TORRES, 2005) e do UNFPA (TORRES, 2002).
} 
Produção de critérios para repartição de transferências governamentais entre o governo federal e Estados e municípios

O governo federal transfere recursos fiscais para Estados e municípios. Essas transferências, muitas delas de caráter constitucional, podem ou não ser relacionadas à provisão de um dado serviço público. Em vários casos, a informação populacional é crucial para a definição dos volumes alocados às diferentes regiões. Vale advertir, porém, que qualquer critério distributivo adotado pode produzir distorções significativas.

Um primeiro problema que se coloca diz respeito à definição do tipo de informação populacional. Quando a repartição é realizada com base no último censo demográfico - como no caso do "Ley de Participación Popular" da Bolívia (HAKKERT, QUINTANA e JOVÉ, 1999) podem ser produzidas distorções importantes em períodos intercensitários, com áreas com crescimento negativo recebendo mais do que proporcionalmente em relação àquelas com intenso crescimento demográfico.

Outros países adotam uma repartição baseada em projeções demográficas para municípios, como o "Fundo de Participação dos Municípios" no Brasil. Nesse caso, além das dificuldades técnicas inerentes a estimativas populacionais para municípios alguns podem ser muito pequenos -, pode existir significativa pressão política sobre o órgão público responsável pelas estimativas. Até recentemente, o Tribunal de Contas da União - que responde pela repartição do Fundo - excluía a possibilidade de que as projeções previssem redução de população para determinados municípios.

Outro critério de repartição diz respeito à divisão de recursos segundo o número de procedimentos realizados no âmbito de uma dada política pública (matrículas escolares, procedimentos médicos, etc.), o que era o critério adotado pelo Sistema Único de Saúde (SUS) na década de 90. Nesse caso, o critério de repartição também pode induzir distorções distributivas, sendo que a maior parte dos recursos tende a ser repassada para regiões - como as áreas metropolitanas - onde o serviço em questão tem uma infra-estrutura mais organizada, com presença de hospitais ou universidades, por exemplo.

A análise sociodemográfica pode dar suporte a esse tipo de processo de decisão de diferentes maneiras, seja produzindo estimativas e projeções como suporte a esse tipo de prática distributiva, seja contribuindo para a análise dos efeitos distributivos de determinadas opções de desenho operacional do programa. Alguns desses desenhos são relativamente complexos, com critérios diferenciados para áreas específicas (como regiões metropolitanas ou áreas rurais, por exemplo), o que também pode implicar distorções.

\section{Focalização de programas sociais}

As políticas focalizadas - como as de transferência de renda - dependem em grande medida de informações sociodemográficas, seja na definição dos grupos populacionais a serem identificados como público-alvo, seja no processo de avaliação desse tipo de política.

No caso da definição dos beneficiários, os critérios adotados partem de informações censitárias ou de grandes amostras de domicílios, permitindo aos governos o estabelecimento de linhas de pobreza a serem focadas, bem como a análise da distribuição espacial da demanda potencial. $\mathrm{Na}$ avaliação da cobertura do programa, as políticas de transferência de renda são muitas vezes (como no caso do programa brasileiro Bolsa-Família) organizadas a partir de cadastros municipais nos quais o usuário potencial é inscrito no programa. Isso prescindiria - em tese - do recurso a informações censitárias, uma vez que as características do beneficiário do programa foram previamente definidas. No entanto, a comparação entre os dados cadastrais e os demográficos, para diferentes áreas geográficas, permite ao analista identificar distorções do programa, relacionadas ao grau de cobertura potencialmente atingido 
e à distribuição geográfica da oferta do serviço. ${ }^{3}$

Em algumas situações, o programa adota algum critério de focalização geográfica - executando a distribuição de benefícios apenas em municípios, distritos ou setores censitários previamente selecionados, ou ainda combinando critérios geográficos e cadastrais. Esse é o caso do Programa Oportunidades, do México, onde o cadastramento de usuários dos programas de transferência de renda é realizado apenas em setores censitários previamente selecionados (GONZÁLEZ DE LA ROCHA, 2005). Assim, os dados demográficos são importantes no sentido de identificar previamente as áreas selecionadas para a implementação do programa.

O analista deverá manipular os dados demográficos na escala desejada (setores censitários, por exemplo), definindo critérios para a seleção das áreas a serem beneficiadas. Para tanto, torna-se necessária a construção de indicadores nessa escala - como o IDH utilizado no Programa Alvorada do Brasil, na escala de municípios -, ou o recurso à análise fatorial e de cluster, como nos estudos que permitiram a definição das áreas a serem atingidas pelo Programa Oportunidades, no México (GARZA, 1999).

Cabe ressaltar, no entanto, que a avaliação desse tipo de programa requer, além de análise de cobertura, estudos sobre o impacto do programa, em que o recurso à informação censitária é mais limitado. (FERNANDEZ e PAZELLO, 2002). Nesse caso, análises quantitativas e qualitativas específicas devem ser realizadas.

Produção de indicadores de base territorial para diversos fins de políticas especificas (segurança pública, saúde, etc.)

Provavelmente, a área na qual mais freqüentemente a análise demográfica tem sido requisitada diz respeito à elaboração de indicadores de base territorial na forma de taxas (morbidade, mortalidade, cobertura, etc.). ${ }^{4} \mathrm{O}$ principal aspecto dessa atividade refere-se ao tradicional esforço de produzir denominadores que servirão de bases para construir tais taxas. No entanto, este tipo de esforço pode implicar uma série de dificuldades nem sempre triviais, particularmente no contexto intra-urbano:

- recortes espaciais de informações administrativas e censitárias não coincidentes. Nem sempre dados censitários e administrativos são organizados para as mesmas unidades de análise. Sobretudo na escala intra-urbana, é muito comum que unidades de planejamento de saúde ou de educação tenham recortes geográficos não consistentes com os recortes oferecidos pelo censo demográfico, impedindo a produção das taxas desejadas. Em alguns casos, o tratamento dessa dificuldade requer a constituição de uma boa cartografia de pequenas áreas e de SIG, que permitam organizar em um mesmo sistema de dados de origens diversas (demográficos e administrativos). Esses sistemas oferecem algumas técnicas que auxiliam o analista a ajustar os diferentes recortes geográficos, como o chamado overlay;

- problemas de consistência entre fontes de dados censitários e aqueles referentes à oferta dos serviços em questão (dados administrativos numa escala de pequenas áreas, e produção de taxas de cobertura). Tais indicadores devem oferecer informações sobre locais com problemas de cobertura, produzindo indicações para a expansão de equipamentos ou extensão da rede. Essas inconsistências têm diferentes naturezas

\footnotetext{
${ }^{3}$ A partir de dados censitários, o analista poderá aferir se uma dada área com elevada concentração de pobreza, por exemplo, está sendo mais beneficiada pelo programa do que uma área mais rica. Não saberá, no entanto, qual a proporção de pobres dessa área que efetivamente recebem o programa. Tal informação de cobertura só pode ser obtida no âmbito de um survey.

${ }^{4}$ Indicadores de base territorial referem-se àqueles construídos segundo recortes geográficos específicos para fins de planejamento, tais como distritos sanitários por exemplo.
} 
relacionadas à forma de coleta da informação, qualidade do registro, etc., além das dificuldades de compatibilização dos recortes geográficos mencionados anteriormente;

- necessidade de estimativas populacionais para períodos intercensitários. Longe dos períodos censitários, o recurso a estimativas populacionais pode auxiliar substancialmente a construção de indicadores intraurbanos. Existem várias alternativas de técnicas nesse caso, inclusive a possibilidade do recurso a indicadores sintomáticos (por exemplo, distribuição de energia elétrica). Em quase todos esses exercícios, distorções são produzidas e o analista tem que interpretar o seu significado para o indicador em questão;

- realização de projeções demográficas para pequenas áreas. Embora esse tipo de projeção seja freqüentemente mencionado na literatura, sua utilização prática para áreas intra-urbanas tem sido pequena, sobretudo em função das dificuldades de prever fenômenos pouco previsíveis, tais como mudança nas regras de zoneamento urbano, abertura de uma nova rodovia ou seu alargamento, implantação de grandes equipamentos urbanos numa dada localidade (indústrias, hospitais, etc.) (JANUZZI, 2002).

Vale destacar que, em alguns casos, o analista precisa produzir - na ausência de alternativas - indicadores relativamente precários, bem como ser capaz de interpretar os erros e vieses possivelmente incorridos nas diferentes regiões em função do uso desses indicadores. Se, por exemplo, para um determinado período intercensitário, o numerador refere-se a dados administrativos relativos ao meio do período e o numerador corresponde à data do censo, o analista tem que ser capaz de prever a subestimação do indicador em áreas de intenso crescimento populacional e a superestimação do mesmo em áreas de perda populacional.
Algumas vezes, torna-se necessário construir indicadores ainda mais problemáticos, como aqueles em que os numeradores e os denominadores não correspondem a indivíduos do mesmo universo. Por exemplo, isso se dá em alguns indicadores intra-urbanos de criminalidade. As vítimas das ocorrências verificadas numa dada localidade podem não ser residentes naquela localidade, como no caso das áreas centrais das maiores cidades. Assim, para a obtenção de indicadores mais adequados do nível de criminalidade, seria necessário estimar a chamada "população flutuante", um tipo de medida relativamente complexa do ponto de vista técnico, envolvendo o recurso a informações sobre fluxos de passageiros e de veículos, nem sempre disponíveis.

Esse tipo de prática pouco convencional para os demógrafos faz muitas vezes parte do dia-a-dia da gestão pública, seja por falta de experiência técnica por parte do gestor, seja em função do timing da política pública em questão. Evidentemente, a melhor estratégia seria contar com estimativas populacionais mais precisas para as diferentes áreas consideradas. Na prática, nem sempre isso é possível, seja devido à ausência de condições técnicas, seja em razão da escassez de tempo ou de recursos (TORRES, 2005).

Planejamento das políticas de infra-estrutura e habitação

Embora a chamada "área de planejamento" encontre-se em crise em diferentes administrações locais e a chamada crise do planejamento tenha se tornado um tema clássico no debate a esse respeito (FRIEDMANN, 1995), existem alguns aspectos do planejamento, particularmente aquele relacionado à oferta de infraestrutura, que continuam a existir em escala local, embora sob diferentes modalidades e arranjos institucionais. Trata-se, nesse caso, de planejar a expansão de redes de infra-estrutura urbana, bem como no que diz respeito ao volume e à localização dos novos investimentos habitacionais. 
Além da análise das tendências do crescimento urbano propriamente dito, a temática da migração pode desempenhar papel significativo. Trata-se de identificar tendências de crescimento demográfico e de fluxos de pessoas (migração pendular) que se traduzam, por um lado, em maior demanda por habitações e, por outro, em pressões sobre o sistema viário. Vale destacar os seguintes elementos:

- no caso da infra-estrutura urbana, decisões sobre o investimento público em transporte e obras de estrutura viária têm que ser tomadas. Alguns desses investimentos têm prazo de maturação (em termos de taxa de retorno do projeto) relativamente longo. Nesse caso, estimativas e projeções demográficas sobre a demanda futura podem exercer papel crucial, permitindo ao gestor identificar as áreas que - de fato - apresentam taxa de retorno significativa;

- para a questão habitacional, o gestor precisaria contar com projeções de domicílios e de demanda futura por domicílios, capazes inclusive de prever as áreas de expansão mais prováveis numa escala regional e local. Infelizmente, em muitas áreas urbanas da América Latina, o setor de habitação não se encontra em condições de antecipar tendências de expansão urbana, agindo de forma meramente reativa às tendências de expansão urbana "nãoantecipadas". ${ }^{5}$

Expansão e manutenção de redes de serviços públicos ou privados - água, esgoto, eletricidade, telefonia, TV a cabo, etc.

Uma das áreas em que a informação demográfica é mais demandada no setor público é aquela relacionada às redes de serviços. Muitas dessas redes (como a de saneamento básico, por exemplo) deman- dam notável volume de investimento e sua expansão tende a ser planejada com relativa antecedência. Em geral, tais redes são administradas por empresas públicas ou privadas que têm em perspectiva algum tipo de retorno financeiro para o investimento.

A expansão da rede de serviços públicos, quando produzida segundo critérios exclusivamente econômico-financeiros por parte das operadoras do serviço, leva em conta três parâmetros principais: tamanho e densidade populacional da área onde o serviço será oferecido; capacidade de pagamento da população local; e dificuldades técnicas envolvidas (proximidades das redes preexistentes, topografia e outras condições do terreno, situação legal da terra, etc.), com implicações para o custo da expansão projetada e a capacidade de retorno do investimento.

Em certos casos, operadoras públicas trabalham segundo critérios extra-econômicos, considerando aspectos de justiça (direito ao serviço), saúde pública (riscos sanitários) e relacionados a reivindicações e pressões comunitárias. Mesmo nesse caso, a definição de prioridades para a expansão dos serviços tende a ser hierarquizada segundo critérios demográficos, numa tentativa de racionalizar o serviço e reduzir perdas financeiras. As principais demandas por informações e técnicas sociodemográficas nesse caso implicam:

- consistência entre fontes de dados de origens diferentes;

- estimativas de população para pequenas áreas (períodos intercensitários), incluindo aquelas referentes a número de domicílio e tamanhos populacionais, e números de domicílios desagregados por grupos de renda;

- identificação de áreas de expansão demográfica recente, sem acesso a serviços e não necessariamente captadas pelo último censo;

\footnotetext{
${ }^{5}$ Ver, mais adiante, discussão sobre a questão da população de favelas e de loteamentos clandestinos, e a necessidade de se construírem "indicadores de alerta" (early warning indicators).
} 
- produção - para pequenas áreas de indicadores sintomáticos indicativos da ausência de determinado serviço, como, por exemplo, taxas de mortalidade infantil e de morbidade por doenças de veiculação hídrica;

- projeções demográficas para pequenas áreas, de modo a subsidiar o planejamento do investimento no longo prazo;

- elaboração de metodologias para estimativa de perdas com ligações clandestinas de água e energia elétrica, por exemplo, através de análises de regressão.

Identificação de locais para a instalação de equipamentos públicos

Ao contrário das redes de serviços públicos, os equipamentos públicos como escolas, postos de saúde, creches e centros comunitários não têm, na lógica de sua implantação, a perspectiva do retorno monetário por parte dos usuários. Em tese, são serviços de caráter distributivo e que levam para sua implantação, em geral, aspectos relacionados à distribuição espacial dos usuários potenciais. Em outras palavras, o desafio aqui está em identificar locais com demanda potencial não atendida e/ou com escolas superlotadas, independentemente da capacidade de pagamento do público-alvo. A rigor, as informações e técnicas sociodemográficas demandadas para auxiliar a implantação desses equipamentos são relativamente distintas das requeridas pelas redes de serviços.

Em primeiro lugar, destaca-se o problema de se definir precisamente a área de influência de um dado equipamento público, para fins de estimativas do tamanho da demanda por esse equipamento. Em alguns países, como nos Estados Unidos, vigora a figura do distrito educacional definido institucionalmente, que obriga o aluno a estudar em escolas do distrito onde reside. Assim, a compatibilização entre oferta e demanda por serviços educacionais é realizada distrito a distrito e são empreendidos esforços para a produção de indicadores demográficos para essa unidade de planejamento. Em outros casos, como no Brasil, não há obrigatoriedade de escolha pela escola existente no distrito. A identificação da área de influência tende a ser relativamente arbitrária, embora algumas técnicas associadas à utilização de sistemas de informação demográfica venham sendo crescentemente utilizadas com esse fim:

- identificação da população residente num raio fixo de distância ao equipamento (por exemplo, num raio de $500 \mathrm{~m}$ da escola). Tal tipo de estimativa implica a existência de dados censitários numa escala bastante detalhada (como setores censitários). Além disso, a estimativa pode ser realizada seja considerando, como parte do raio de influência, os setores censitários cujo centro geográfico (centroid) esteja dentro desse raio, seja através de técnicas que permitam a repartição da população daqueles setores que não se encontram totalmente dentro desse raio. A técnica mais utilizada, nesse caso, é o chamado overlay, em que dados do setor censitário são atribuídos ao raio de influência, na proporção em que a área do setor coincide com a superfície do raio de influência. ${ }^{6}$ Tratase evidentemente de um recurso limitado, que só deve ser utilizado quando o número de setores censitários contidos dentro do raio for relativamente grande, fazendo com que o recurso à repartição da população seja aplicado num número limitado de setores e permitindo a ocorrência do processo de "compensação de erros" nesses casos;

- utilização de recursos automáticos como o "algoritmo de Voronoy", que estima a área de influência a partir da distância relativa dos diversos equipamentos de uma dada rede.

\footnotetext{
${ }^{6}$ Para uma discussão mais cuidadosa sobre o tema do overlay, ver Torres e Marques (2005), em particular o anexo metodológico.
} 
Vários softwares de SIG dispõem dessa funcionalidade, apesar de se tratar de um ferramenta relativamente limitada, uma vez que as áreas construídas a partir desse recurso não levam em conta barreiras físicas (rios, estradas, etc.), nem os percursos urbanos efetivamente percorridos pela população. ${ }^{7}$ Estimativas de população podem ser realizadas de modo semelhante ao mencionado no caso do raio de influência, consideradas as mesmas restrições apontadas.

Uma vez identificadas as áreas de influência de um dado equipamento público, coloca-se o problema de produzir estimativas populacionais intercensitárias e projeções para áreas com recortes geográficos não convencionais, isto é, não necessariamente consistentes com o recorte geográfico original dos setores censitários, distritos e municípios, o que implica, como mencionado, o recurso a técnicas de repartições de dados. Realizadas essas etapas, as questões em geral são similares àquelas observadas anteriormente:

- consistência entre fontes de dados censitários e os relativos à oferta dos serviços para cada área de influência, e produção de taxas de cobertura;

- estimativas de população para pequenas áreas (períodos intercensitários), inclusive para grupos etários específicos, tais como crianças, no caso de equipamentos de educação, ou idosos, no que se refere a equipamentos de saúde. Muitas vezes análises de coorte são necessárias particularmente em situações de descontinuidade demográfica ou de crescimento demográfico substancial;

- identificação de áreas de expansão demográfica recente, sem acesso a serviços e não necessariamente captadas pelo último censo. Isso pode ser realizado através de indica- dores sintomáticos (nascimentos, por exemplo) ou com recurso a fotografias aéreas e imagens de satélite;

- produção - para as áreas de influência dos equipamentos - de indicadores sintomáticos indicativos da ausência de determinado serviço, como, por exemplo, taxas de analfabetismo juvenil e taxas de morbidade;

- projeções demográficas para áreas de influência, de modo a subsidiar o planejamento do investimento no longo prazo.

Caracterização de áreas de assentamentos precários (bairros, favelas, loteamentos clandestinos)

Uma outra questão importante na gestão urbana de grandes cidades de países em desenvolvimento refere-se à identificação e caracterização dos chamados assentamentos precários, que são áreas de expansão urbana fora da lógica do planejamento urbano oficial. Algumas dessas áreas constituem invasão de terra pública ou privada; outras correspondem a loteamentos urbanos fora dos parâmetros legais definidos pela administração municipal. Alguns autores estimam que essas modalidades de uso do solo abrangem 30\% do total de domicílios das principais cidades latino-americanas (LIM, 1995). ${ }^{8}$

Uma primeira questão diz respeito à identificação desse tipo de assentamento urbano. Crescentemente, as administrações municipais têm recorrido a fotos aéreas e imagens de satélite para a identificação dessas localidades, que, por suas características urbanísticas, são de fácil observação. No entanto, mesmo quando identificadas, as estimativas de população desse tipo de assentamento envolvem aspectos particularmente complexos, relacionados ao pequeno tamanho dessas áreas e às altas densidades existentes.

\footnotetext{
${ }^{7}$ Isso faz com que um dado equipamento, mesmo sendo o mais próximo, seja inacessível para usuários localizados além dessa barreira.

${ }^{8}$ No caso de São Paulo, estimativas da Secretaria Municipal de Habitação calculam essa proporção em $26 \%$ do total de domicílios (HABI, 2003).
} 
Muitas vezes, o censo demográfico não é capaz de identificar essas áreas adequadamente, uma vez que o conceito de setor censitário subnormal - voltado para o planejamento operacional do censo - é relativamente limitado. Além de problemas de cobertura, os subnormais são problemáticos sobretudo quando as favelas ou formas análogas de ocupação têm uma dimensão geográfica muito pequena, inferior ao tamanho médio do setor censitário. No caso de São Paulo, por exemplo, o município buscou fontes alternativas e realizou estimativas da população em favelas, a partir de pesquisas amostrais com resultados muito controversos. ${ }^{9}$

Uma alternativa utilizada por alguns autores foi o recurso a estimativas baseadas em hipóteses sobre a densidade demográfica, uma vez que as áreas com este tipo de ocupação podem ser bem estabelecidas no âmbito de um SIG, a partir das fotos aéreas e imagens de satélite. Assume-se nesse caso, por exemplo, que a densidade demográfica de uma pequena favela identificada por meio de imagem de satélite é similar àquela do setor censitário subnormal mais próximo, cuja população foi adequadamente estimada pelo censo (MARQUES, TORRES e SARAIVA, 2003).

\section{Avaliação do impacto de obras de infra- estrutura}

Obras de infra-estrutura, como estradas, aeroportos, hidroelétricas, etc., provocam muitas vezes um significativo impacto sobre a vida de populações locais. Em muitos casos, populações têm que ser deslocadas. Isso tem sido objeto de sucessivos conflitos entre governo e movimentos sociais por toda a América Latina. Em outras situações, legislações nacionais obrigam o governo nacional ou o executor da obra a apresentar um estudo de impacto, inclusive estabelecendo as chamadas "ações mitigadoras", isto é, aquelas destinadas a reduzir ou atenuar o impacto causado.

Estimativas de impacto desse tipo são relativamente complexas, sobretudo quando envolvem dinâmicas relacionadas ao mundo natural. Por exemplo, uma obra hidroelétrica pode alterar as condições de pesca em um rio a dezenas de quilômetros abaixo da obra, afetando as condições de vida de uma população ribeirinha. Assim, esses estudos normalmente envolvem grupos interdisciplinares, com biólogos, epidemiólogos, geólogos, geógrafos, profissionais de engenharia e cientistas sociais.

O primeiro desafio analítico diz respeito à definição da área de influência do projeto. Embora esse procedimento seja, em muitos casos, realizado de modo ad-hoc, aspectos técnicos diversos - tais como dados epidemiológicos e informações relativas à densidade e distribuição da população podem contribuir significativamente para esse tipo de tomada de decisão. Uma vez definida a área de influência, a análise sociodemográfica envolvida implica uma série de atividades distintas:

- estimar o tamanho da população atingida, o que significa recorrer a estimativas populacionais para recortes geográficos não convencionais (mencionadas anteriormente), facilitadas pelo recurso ao SIG;

- gerar indicadores de modo a avaliar as condições de vida dessa população, inclusive os aspectos relacionados a saúde e trabalho, no sentido de garantir, na nova situação (com ou sem remoção), a não-deterioração das condições de vida;

- estimar os custos das indenizações a serem pagas (em caso de remoções e desapropriações), bem como assegurar que o projeto de assentamento dos removidos garanta condições adequadas para essas populações.

\footnotetext{
${ }^{9}$ A equipe da Fipe/USP, contratada pela prefeitura de São Paulo, estimou uma taxa de crescimento demográfico da população em áreas de favelas superior a 15\% ao ano para o período de 1987 (data do primeiro censo de favelas da prefeitura) a 1993 (data da pesquisa da Fipe). Para que tal taxa se verificasse, teria sido necessária uma substancial migração de população de áreas nãofaveladas para áreas de favela. Além disso, os dados dos Censos de 1991 e 2000 contrariaram claramente tal estimativa (TORRES e MARQUES, 2002).
} 
Identificação de populações em situações de "perigo"

Existem, nas áreas urbanas e rurais, vários perigos (hazards) relacionados a fenômenos naturais, tais como inundações, terremotos, deslizamentos, etc. Há também problemas sanitários referentes à proximidade do domicílio a locais com vetores de doenças transmissíveis (cursos d'água, lixões, indústrias poluentes, etc.). Na verdade, os riscos incorridos pelos diferentes grupos populacionais dependem não apenas das condições ambientais do local de moradia (topografia, condições geológicas, ventos, etc.), mas - principalmente do nível de informação da população em situação de risco e das qualidades construtivas do domicílio. De modo geral, domicílios improvisados e malconstruídos são muito mais vulneráveis a riscos desse tipo do que aqueles bem protegidos e construídos (TORRES, 2000).

Em vista desses elementos, um projeto de identificação de populações em situação de perigo envolve as seguintes etapas:

- identificação de um fenômeno ambiental "perigoso";

- identificação de áreas com elevada probabilidade de ocorrência (ou de alta intensidade) de tal fenômeno;

- estimativa da população residente nesses locais. Novamente, há que se pensar aqui - como nos itens anteriores - na estimativa populacional para áreas com recortes populacionais não convencionais;

- identificação das características sociodemográficas dessa população, bem como das características dos domicílios;

- elaboração de um plano de redução de riscos, que pode envolver, em alguns casos, a remoção de população.

Geração de indicadores de alerta (early warning indicators)

Nas áreas urbanas de crescimento rápido é comum o surgimento de ocupações não detectadas pelo último censo. Essas áreas implicam significativo desafio para o planejamento, que muitas vezes sequer consegue registrar oficialmente sua existência. Por isso mesmo, são menos providas de infra-estrutura básica, bem como de escolas e postos de saúde (BANERJEE, 1996).

Nessas circunstâncias, os chamados indicadores de alerta (early warning indicators) propõem-se a advertir o sistema de planejamento a respeito da ocorrência de expansões urbanas inesperadas. $\mathrm{Na}$ verdade, indicadores de alerta são aqueles constituídos com o objetivo de apontar mudanças bruscas no tamanho populacional de um dado local no curto prazo (BANERJEE, 1996). Trata-se, por exemplo, do caso da invasão de áreas urbanas periféricas e/ou de unidades de conservação, que quando percebidas pelo setor público já se tornaram fatos consumados.

Para tanto, o analista terá que recorrer às diferentes fontes de dados secundárias a seu dispor, bem como a outras informações menos convencionais, como fotografias aéreas e imagens de satélite. Quando possível, dados como os proporcionados pelo registro civil permitem também produzir evidências a respeito do tamanho populacional desses locais. Outras fontes de dados, como o consumo de energia elétrica e de gás, quando disponíveis, também podem ser utilizadas com essa finalidade.

Nesse contexto, requerem-se as seguintes informações e tratamento do dado sociodemográfico:

- sobreposição cartográfica (no âmbito de um SIG) de imagens de satélite ou fotos aéreas com dados sobre distribuição e densidade demográfica dos setores censitários. Tais procedimentos permitem ao analista identificar áreas atualmente existentes e não-cobertas pelo último censo;

- geocodificação de registros civis e/ ou de outras fontes de dados, tais como aquelas relativas ao consumo de energia elétrica e gás;

- produção de estimativas populacionais para essas áreas, a partir dessas fontes ou de hipóteses rela- 
cionadas à densidade demográfica média das áreas observadas.

\section{A questão da desagregação espacial da informação}

A lista de problemas discutida anteriormente aponta claramente para a necessidade de pensarmos com cuidado a questão da desagregação espacial da informação em grandes áreas urbanas. Nas cidades de pequeno porte, os gestores locais têm condições de inspecionar pessoalmente cada escola e posto de saúde, bem como podem conversar com a população local, tendo capacidade de identificar facilmente as situações mais problemáticas. No entanto, esta questão torna-se muito mais complexa nas grandes áreas urbanas, uma vez que tal gestão pode envolver milhares de escolas, centenas de hospitais e postos de saúde, bem como uma área urbana em permanente expansão.

Tal fenômeno leva a que, crescentemente, o tratamento da informação para políticas sociais tenha que assumir um caráter intra-urbano. Em outras palavras, os dados censitários e demais indicadores municipais, tradicionalmente produzidos pelas agências estatísticas para fins de planejamento público, são claramente insuficientes do ponto de vista da gestão urbana de grandes metrópoles. Nesses locais, os indicadores sociais precisam ser desagregados territorialmente, por várias razões:

- as significativas desigualdades intraurbanas, longamente documentadas na literatura sobre a área urbana na América Latina (MARQUES e TORRES, 2005; MARTINE, 2001; GUGLER, 1996; MASSEY, 1996; STEIN, 1992; SCHTEINGART, 1989), implicam a existência de importantes diferenciais em termos de indicadores, tais como taxa de mortalidade infantil, taxa de gravidez na adolescência e outros. Isso faz com que seja particularmente importante dotar o Estado da capacidade de identificar esses diferenciais, de modo a atuar mais eficientemente em cada situação encontrada. Infelizmente, a produção de dados e indicadores na escala intra-urbana está muito pouco desenvolvida, embora algum avanço recente esteja ocorrendo em função da emergência dos SIGs;

- a existência de significativos níveis de irregularidade fundiária - estimados para a América Latina como algo em torno de $30 \%$ nas mais importantes áreas urbanas (LIM, 1995) - faz com o Estado tenha pouca informação sobre esses locais. Em muitas administrações municipais, a principal fonte de dados sobre a evolução e distribuição da população (e de seus domicílios) corresponde aos chamados cadastros imobiliários, utilizados para fins de arrecadação fiscal. Como esses cadastros não registram as áreas de ocupação irregular, muitas vezes essa população torna-se invisível para as políticas públicas urbanas. Dados censitários podem minorar esses problemas apenas quando são disponibilizados em escala bastante desagregada (como setores censitários) e tratados a partir de SIG, permitindo ao gestor identificar os locais sub-registrados pelos cadastros imobiliários;

- mesmo áreas que registram taxas de crescimento relativamente moderadas ou negativas, como o caso das cidades do Rio de Janeiro e de São Paulo, podem apresentar - na escala intra-urbana - dinâmicas demográficas relativamente "selvagens", com perda populacional nas áreas centrais e forte crescimento demográfico naquelas periféricas (MARQUES e TORRES, 2005). E esse tipo de dinâmica urbana pode constituir um importante desafio para a gestão pública. Mesmo que, por exemplo, exista teoricamente uma oferta adequada de serviços de saúde, compatível com o tamanho da população existente, esse tipo de 
dinâmica induz a ocorrência de posto de saúde subutilizados nas áreas centrais e postos superlotados em periferias de forte crescimento demográfico, pois oferta e demanda não estão necessariamente ajustadas numa escala intra-urbana.

Outro problema freqüentemente observado nas políticas sociais intra-urbanas diz respeito a problemas de compatibilidade entre os recortes geográficos relativos a divisões administrativas propostas por uma dada política (por exemplo, o distrito sanitário) e os recortes geográficos relevantes do ponto de vista da identificação da demanda efetivamente existente. Nas políticas sociais intra-urbanas, os gestores públicos demandam, com freqüência, dados para recortes geográficos não necessariamente compatíveis com os permitidos pelo Censo Demográfico e com aqueles utilizados por outras fontes de dados administrativas: área de influência de escolas; distritos de saúde; unidade de planejamento policial; conjuntos habitacionais; etc. Embora os SIGs modernos ofereçam algumas alternativas técnicas para contornar esse tipo de problema, tais como o algoritmo de Voronoy e as técnicas de overlay, muito pouca discussão a respeito dessas técnicas e de suas conseqüências analíticas tem sido feita pela comunidade de produtores de informação. Além disso, poucas administrações públicas dispõem desses sistemas com qualidade e sofisticação necessárias e com competência para utilizá-los adequadamente.

Em tese, bases de dados com informações ponto-a-ponto, como o registro civil e outros cadastros relevantes, podem ser endereçadas automaticamente (address matching) por meio de SIG, o que permitiria ao analista dispor de informações adequadas para qualquer recorte geográfico desejado. Infelizmente, além dos problemas técnicos relativos à qualidade dos dados cadastrais - quase sempre problemáticos (TORRES, 2005) -, o endereçamento automático implica a existência de mapas eletrônicos de ruas com cobertura adequada, incluindo mais extensamente as áreas mais pobres. Embora o Censo Demográfico de 2000 tenha avançado substancialmente na produção de cartografias eletrônicas para pequenas áreas, como setores censitários, o IBGE não produz e atualiza um mapa de ruas passível de permitir a geocodificação. Quando existente, este tipo de cartografia é elaborado por empresas privadas, não necessariamente preocupadas com a cobertura das áreas mais pobres e das ocupações irregulares. Como conseqüência, o recurso ao endereçamento eletrônico pode acarretar distorções importantes, sobretudo no que diz respeito ao sub-registro da população cadastrada nas áreas mais pobres da cidade. Também nesse caso, trata-se de uma ferramenta poderosa, que demanda usuários treinados e analistas competentes para lidar adequadamente com o possível sub-registro.

\section{Discussão}

A rigor, a informação desagregada espacialmente permite ao analista refletir sobre um dos mais complexos problemas da gestão urbana: o de onde agir. Tradicionalmente, essa questão tem sido resolvida pela intermediação de representantes políticos ou de movimentos sociais. Segundo esse modelo de administração da demanda, recebem investimentos públicos aquelas áreas (e grupos) que fazem suas reivindicações serem ouvidas pelo governo local. Obviamente, esta forma de atendimento da demanda por serviços públicos pode ter impactos distributivos importantes. Os segmentos populacionais menos informados e menos organizados têm, em geral, muito menos chances de reivindi-carem suas demandas e fazê-las chegar aos gestores governamentais.

Com informações e indicadores adequados, o gestor tem condições de identificar a demanda por meios próprios, independentemente de terem sido verbalizadas ou não, bem como de priorizá-las segundo critérios técnicos. Lidar com o problema de "onde agir" implica pensar quatro dimensões distintas: 
- equipamentos públicos nem sempre estão localizados onde eles são mais necessários. Por causa dos diferentes ritmos de crescimento intraurbano e intra-regional, é possível, por exemplo, identificar escolas com vagas não preenchidas e locais, no mesmo município, com crianças sem escola (mesmo quando a taxa de cobertura do município é próxima de $100 \%)$. Isso ocorre em parte porque os equipamentos sociais são caros, e professores e médicos resistem em trabalhar em locais pobres e distantes das maiores aglomerações urbanas. Por outro lado, os custos de transporte são mais elevados para os mais pobres e as pessoas acabam buscando serviços próximos, mas não necessariamente os mais adequados. Sistemas de informações desagregadas espacialmente permitem aos gestores direcionar recursos para áreas efetivamente necessitadas;

- em extensas regiões metropolitanas, a estrutura etária pode variar substancialmente nas diferentes localidades da cidade, com populações mais idosas geralmente residindo em áreas centrais e segmentos bastante jovens e altas proporções de crianças vivendo nas áreas de ocupação recente - muitas vezes localizadas na periferia urbana. Tais variações têm importantes impactos para as políticas de saúde e educação - bem como para políticas e projetos de intervenção urbana em geral - e precisam ser identificadas de modo adequado, para que possam informar tais políticas. Em outras palavras, a distribuição de serviços e de benefícios sociais precisa ser consistente com a distribuição da população-alvo das políticas, como idosos e crianças. O mesmo argumento se aplica à distribuição heterogênea no espaço das pessoas de baixa renda;
- indicadores sociais negativos são cumulativos territorialmente. É possível encontrar pessoas vivendo em áreas que apresentem, simultaneamente, risco ambiental - como as próximas a lixões - e falta de saneamento adequado, equipamentos de educação e serviços sociais. Muitas vezes essas áreas possuem altas concentrações de crianças e de mulheres responsáveis pelo domicílio. Este tipo de circunstância desafia o enfoque tradicional da oferta de serviços públicos, baseado em diferentes instâncias administrativas que não necessariamente trocam informações entre si;

- a segregação residencial pode ter impactos relevantes para as políticas públicas. Segundo a literatura sobre o tema, áreas segregadas não são apenas aquelas com altas concentrações de pobres. Técnicas estatísticas, como o "Moran Local", permitem facilmente identificar as regiões mais claramente segregadas no âmbito de parâmetro selecionado (renda, escolaridade, etc.). Residir em tais localidades afeta de diferentes formas as perspectivas de vida desta população, induzindo diversas distorções: riscos para a saúde, com impacto sobre a capacidade de trabalho e renda; custo de moradia como proporção da renda, afetando a renda disponível para o consumo; pior acesso ao mercado de trabalho; pior performance escolar, mesmo quando controlada por renda e outras características socioeconômicas. Estes efeitos também são denominados de "externalidades negativas" derivadas do tipo de local de moradia (YIENGER, 2001; EASTERLY e LEVINE, 2001; TORRES, 2004).

Informações desagregadas territorialmente permitem ao analista bem treinado identificar tanto as áreas com maiores distorções entre oferta e demanda por serviços como aquelas que apresentam 
cumulatividade de indicadores sociais negativos ou que são segregadas em termos residenciais. Evidentemente, tais informações precisam ser organizadas em um SIG, principalmente em áreas urbanas de grande porte.

Em síntese, os SIGs permitem realizar uma série de procedimentos relativamente problemáticos em formatos analógicos, tais como trabalhar com uma escala geográfica muito detalhada (pontos, setores censitários, etc.). Sistemas desse tipo também permitem ao analista trabalhar com bases de dados de origens distintas, numa escala geográfica detalhada, compatibilizando, por exemplo, o número de alunos numa dada escola com o de crianças nos setores censitários mais próximos. Finalmente, esses sistemas possibilitam ao analista introduzir num banco de dados tradicional informação "geográfica" anteriormente não disponível, tais como a distância média de um determinado setor censitário à escola mais próxima, o que permite a construção de novos indicadores de acesso a serviços públicos não disponíveis anteriormente e de grande utilidade operacional.

Lidar com essas questões coloca uma série de desafios para a demografia enquanto disciplina. Em primeiro lugar, é importante que esta área de estudo seja capaz de desenvolver e/ou disseminar métodos demográficos de estimativas populacionais para regiões intra-urbanas (distritos, etc.) em períodos intercensitários, que sejam práticos e passíveis de produção de modo compatível com o timing dos processos de tomada de decisão. Métodos que considerem a utilização de registros civis, por exemplo, somente têm utilidade nos locais onde esses registros são

\section{Referências bibliográficas}

ARRETCHE, M.; RODRIGUES, V. (Eds.). Descentralização das políticas sociais no Brasil. São Paulo: Fundap/Fapesp/lpea, 1998.

BANERJEE, T. Role of indicators in monitoring growing urban regions: the case of planning in India's National Capital desagregáveis em escala intra-urbana. No entanto, a utilização de ferramentas de SIG com esse fim, como o endereçamento automático (address matching) do registro civil, encontra barreiras significativas em função dos mapas de ruas existentes na maior parte das cidades do Brasil.

Nesse sentido, é também preciso, em segundo lugar, estimular as agências estatísticas nacional e estaduais a produzirem e atualizarem mapas de ruas por ocasião da realização dos censos nacionais ou outras pesquisas de grande porte. Embora possa existir cartografia disponível em nível local, essa cartografia é normalmente do tipo analógico e não cobre todas as áreas habitadas, sendo particularmente deficientes naquelas invadidas ou de ocupação irregular. No caso do Censo, essa atividade pode ser realizada de modo paralelo à produção dos dados digitalizados por setores censitários. Além de sua óbvia utilidade do ponto de vista da gestão local, mapas de ruas digitalizados adequadamente podem facilitar sobremaneira a própria realização dos censos.

Em síntese, o desenvolvimento da área de demografia aplicada a políticas sociais precisa superar diferentes obstáculos pertinentes tanto à tradição profissional da demografia, quanto à produção de dados adequados para esse fim. Embora esse campo seja pouco desenvolvido em nosso universo profissional, milhares de gestores urbanos em todo o país tratam de tomar decisões sobre a alocação de recursos públicos, localização de equipamentos, montagem de redes de serviços, etc. Contribuir para a ação desses gestores é provavelmente um dos principais desafios dessa disciplina nos próximos anos.

Region. Journal of the American Planning Association, v 62, n 2, 1996.

DEMERS, M. N. Fundamentals of Geographic Information Systems. New York: John Wiley \& Sons Inc., 2000.

EASTERLY, W.; LEVINE, R. It's not factor accumulation: stylized facts and growth 
models. World Bank Economic Review,15, n. 2, 2001.

FINOT, I. Descentralización, transferencias territoriales y desarrollo local. Revista de la CEPAL, 86, 2005.

FERNANDES, R.; PAZZELO, E. Avaliação de políticas sociais: incentivos adversos, focalização e impacto. São Paulo: FEA-USP, 2002. Mimeografado.

FRIEDMANN, J. Planning in the public domain: discourse and praxis. In: STEON, J.M. Classic readings in urban planning: an introduction. New York: McGraw-Hill, 1995, p. 74-79.

GARZA, G. Atlas demográfico de México. Mexico City: Conapo/Progresa, 1999.

GONZÁLEZ DE LA ROCHA, M. Familias y política social en México. El caso de oportunidades. Trabalho apresentado na Reunión de expertos "Política hacia las famílias, protección e inclusión sociales". Santiago: Cepal, 2005.

GUGLER, J. The urban transformation of the developing world. New York: Oxford University Press, 1996.

HABI - Secretaria de Habitação de São Paulo. Plano habitacional de São Paulo. São Paulo: Habi-PMSP, 2003. Mimeografado.

HAKKERT, R.; QUINTANA, C.; JOVÉ, G. The decentralization of reproductive health services and its implications for UNFPA assistance: the case of Bolívia. La Paz: UNFPA, 1999. Mimeografado.

JANUZZI, P. M. Indicadores sociais no Brasil: conceitos fontes e aplicações. Campinas: Alínea, 2001.

Projeções populacionais para pequeníssimas áreas: método e resultado para os distritos da cidade de São Paulo em 2010. ENCONTRO NACIONAL DE ESTUDOS POPULACIONAIS, 13, Ouro Preto, 2002. Anais... Belo Horizonte: ABEP, 2002.

LIM, G.-C. Housing policies for urban poor in developing countries. In: STEIN, J. M.
Classic readings in urban planning. New York: McGraw-Hill, 1995, p. 521-537.

MARQUES, E.; TORRES, H. G. (Eds.). São Paulo: segregação, pobreza e desigualdade social. São Paulo: Editora do Senac, 2005.

MARQUES, E.; TORRES, H. G.; SARAIVA, C. Favelas no Município de São Paulo estimativas de população para os anos de 1991, 1996 e 2000. Revista Brasileira de Estudos Urbanos e Regionais, vol. 5, № 1, p.15-30, 2003

MARTIN, D. Geographic Information Systems: socioeconomic applications. London: Routledge, 1996.

MARTINE, G. The sustainable use of space: advancing the population/environment agenda. Nova York: Population-Environment Research Network, 2001.

MARTINE, G.; HAKKERT, R.; GUZMAN, J. M. Population and development strategies: responding to new challenges. Mexico City: UNFPA Country Support Team for Latin American and Caribbean, 2000.

MASSEY, D. S. The age of extremes: concentrated affluence and poverty in the 21st century". Demography, 33, n.4, p.395412, 1996.

SCHTEINGART, M. Los produtores del espacio habitable: Estado, empresa y sociedad en la Ciudad de México. Mexico City: El Colégio de México, 1989.

STEIN, $M$ et alii. Urban research in the developing world: towards an agenda for the 1990s. Toronto: University of Toronto, Center for Community Studies, 1992.

TORRES, H.G. A demografia do risco ambiental. In: TORRES, H.G.; COSTA, H.M. População e meio ambiente: debates e desafios. São Paulo: Editora do Senac, 2000, p. 53-74.

TORRES, H.G.; MARQUES, E.C. Tamanho populacional das favelas paulistanas. Ou os grandes números e a falência do debate sobre a metrópole. ENCONTRO NACIONAL DE ESTUDOS POPULACIONAIS, 13, Ouro Preto, 2002. Anais... Belo Horizonte: ABEP, 2002. 
TORRES, H.G. Social policies for the urban poor: the role of population information systems. Mexico City: UNFPA Country Support Team for Latin America and Caribbean, 2002 (Working Papers Series, 24).

. Segregação residencial e políticas públicas: São Paulo na década de 1990. Revista Brasileira de Ciências Sociais, v. 19 , n. 54 , p.41-56, 2004.
Informação demográfica e políticas públicas na escala regional e local. Paper apresentado na "Reunión de expertos sobre población y desarrollo local". Santiago, Chile: Celade/Cepal, 2005.

YIENGER, J. Housing discrimination and residential segregation as causes of poverty. In: DANZIGER, S. H.; HAVERMAN, R.H. Understanding poverty. New York: Russell Sage, 2001, p. 359-391.

\section{Abstract \\ Urban demography and social policy}

This article discusses potential contributions made by demographic analysis to urban public policies. Ten situations pertaining to social policy-making where demographic information may provide a substantial contribution are featured here. Additionally, two other important aspects are highlighted - namely, the issue of de-aggregating spatial information, and the need to use geographic information systems.

Key words: Applied demographics. Public policies. Geographic information systems. Urban demographics.

Recebido para publicação em 23/01/2006 Aceito para publicação em 17/03/2006. 